\title{
The T160A hemagglutinin substitution affects not only receptor binding property but also transmissibility of H5N1 clade 2.3.4 avian influenza virus in guinea pigs
}

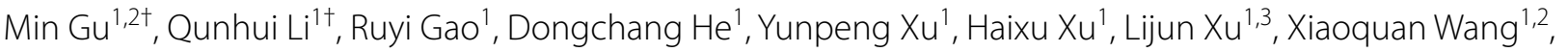 \\ Jiao Hu ${ }^{1,2}$, Xiaowen $\mathrm{Liu}^{1,2}$, Shunlin Hu${ }^{1,2}$, Daxin Peng ${ }^{1,2,4}$, Xinan Jiao ${ }^{1,2,4}$ and Xiufan Liu ${ }^{1,2,4^{*}}$
}

\begin{abstract}
We generated and characterized site-directed HA mutants on the genetic backbone of H5N1 clade 2.3.4 virus preferentially binding to $a-2,3$ receptors in order to identify the key determinants in hemagglutinin rendering the dual affinity to both a-2,3 (avian-type) and a-2,6 (human-type) linked sialic acid receptors of the current clade 2.3.4.4 H5NX subtype avian influenza reassortants. The results show that the T160A substitution resulted in the loss of a glycosylation site at $158 \mathrm{~N}$ and led not only to enhanced binding specificity for human-type receptors but also transmissibility among guinea pigs, which could be considered as an important molecular marker for assessing pandemic potential of $\mathrm{H} 5$ subtype avian influenza isolates.
\end{abstract}

\section{Introduction, methods, and results}

The highly pathogenic Asian-lineage avian influenza (HPAI) H5N1 viruses pose a serious pandemic threat due to their high virulence and mortality, and their increasingly expanding host range, as well as the significant ongoing evolution toward efficient transmission in mammalian models [1]. Despite the fact that the HPAI H5N1 viruses have been globally distributed and endemic in several countries, the direct transmission from avian species to human beings still remains a relatively rare event [2]. As acknowledged, the preference of hemagglutinin (HA) of influenza A virus for particular glycan-linkage of terminal sialic acid (SA) moieties on susceptible cells is a key determinant of viral host range and tissue tropism [3]. Generally, avian influenza viruses preferentially bind to SA in $\alpha-2,3$ linkage with the vicinal galactose $(\alpha-2,3 \mathrm{SA})$, which predominates in the intestinal tracts of

\footnotetext{
*Correspondence: xfliu@yzu.edu.cn

${ }^{\dagger} \mathrm{Min}$ Gu and Qunhui Li contributed equally to this work

${ }^{1}$ College of Veterinary Medicine, Yangzhou University, Yangzhou, Jiangsu 225009, China

Full list of author information is available at the end of the article
}

waterfowl, the natural reservoir of influenza A viruses. In contrast, human-adapted influenza viruses showed selective binding affinity to SA in $\alpha-2,6$ pattern $(\alpha-2,6 \mathrm{SA})$, the major linkage type in human respiratory epithelia [4].

According to the literature, some particular amino acid substitutions in the vicinity of the HA receptor-binding domain (RBD) that contributed to the adaptation of avian influenza viruses to human hosts have been elucidated for the previous influenza pandemic subtypes, even if just one or two critical residues could be responsible for host switching since the RBD pocket is shallow. For instance, the E190D (H3 numbering throughout the paper) and G225D/E mutations in HA of the H1N1/1918 pandemic viruses, as well as the Q226L and G228S substitutions in $\mathrm{HA}$ of the $\mathrm{H} 2 \mathrm{~N} 2 / 1957$ and $\mathrm{H} 3 \mathrm{~N} 2 / 1968$ pandemic viruses, correlated with the conversion of binding preference to SA receptors from $\alpha-2,3$ to $\alpha-2,6$ type $[3,5-7]$. However, most HPAI H5N1 viruses do not bind to $\alpha-2,6$ receptors with high affinity $[8,9]$, although the number of cumulative human cases available has already reached 854 with over $50 \%$ mortality until July, 2016. And it is widely believed that the restriction of receptor binding specificity is the major factor preventing the $\mathrm{H} 5 \mathrm{~N} 1$ virus 
from efficiently transmitting from person to person and causing a pandemic [10].

In the last few years, natural reassortant HPAI H5NX viruses with various $\mathrm{NA}$ subtypes other than $\mathrm{N} 1$, at least including N2, N6 and N8, in the newly designated clade 2.3.4.4 affiliating to clade 2.3.4 have been circulating in many areas in China $[11,12]$. In addition, the novel H5N8 virus has invaded multiple countries across Asia, Europe and North-America mainly via migratory birds, leading to further subsequent reassortment with local lineages of influenza virus in wild birds to generate devastating variants like the HPAI H5N2 [11, 13]. Moreover, the H5N6 clade 2.3.4.4 expanding to Laos and Viet Nam gained ecological niches there and not only resulted in losses to the poultry industry but also caused human death [14-16].

Noteworthy, as compared with the $\mathrm{H} 5 \mathrm{~N} 1$ viruses in clade 2.3.4 showing complete $\alpha-2,3$ receptor specificity, most of those above mentioned HPAI H5NX reassortant viruses can bind to both $\alpha-2,3$ (avian-type) and $\alpha-2,6$ (human-type) linked sialic acid receptors [17-22]. However, the molecular basis conferring this dual receptor binding property has not been clearly described yet. Therefore in this study, we generated a series of sitedirected HA mutants based on the genetic backbone of $\mathrm{H} 5 \mathrm{~N} 1$ clade 2.3.4 virus, to determine the key amino acid contributing to the increased viral affinity to $\alpha-2,6$ receptors and the effect on viral transmissibility among guinea pigs. All experiments involving live viruses were conducted in animal biosafety level 3 facilities in Yangzhou University. All the animal studies were permitted by the Department of Science and Technology of the Jiangsu Province (license ID: SYXK (SU) 2016-0019), and complied with the guidelines of the institutional administrative committee and ethics committee of laboratory animals.

Firstly, the HA sequences of the previously reported H5NX clade 2.3.4.4 reassortants possessing dual receptor binding property were retrieved from the GenBank and GISAID public databases to be aligned with that of $\mathrm{H} 5 \mathrm{~N} 1$ clade 2.3.4 virus A/mallard/Huadong/S/2005 (HD/05) exhibiting just $\alpha-2,3$ receptor specificity through the software MEGA (version 6.06). As shown in Table 1, six consistent amino acid substitutions all located in the HA1 subunit including K90R, T160A, K222Q, S227R, N244H and A266T were identified (Additional file 1). In particular, we noticed that the $\mathrm{T}$ to A mutation at site 160 simultaneously resulted in the loss of the glycosylation site at position $158 \mathrm{~N}$ of the HA protein.

Subsequently, we introduced each of these six substitutions individually into the $\mathrm{HA}$ of $\mathrm{HD} / 05$ virus by a site-directed mutagenesis kit (TransGen, Beijing, China) to generate site-specific HA mutants via reverse genetics. Briefly, a mixture of 293T and MDCK cells was transfected with PHW2000-vectored plasmids encoding all eight influenza A virus genes using the PolyFect transfection reagent (Qiagen, Valencia, CA, USA) as recommended by the manufacturer. After $48 \mathrm{~h}$, the supernatant was harvested and inoculated into 10-day-old SPF embryonated chicken eggs for propagation of stock virus. All of the rescued viruses were confirmed by sequencing of their viral RNA, and no other amino acid changes in the viral genome apart from the expected mutated site in HA genes were observed, even when the rescued viruses were passaged for 5 generations in eggs.

To evaluate the receptor binding property of the six rescued HA mutants, we conducted the solid-phase direct binding assay with corresponding $\alpha-2,3$ and $\alpha-2,6$ linked glycans as previously described [17]. In short, 96-well microtiter plates were coated with the appropriate concentration of synthetic sialylglycopolymers Neu5Aca2-3Galb1-4GlcNAcb (3'SLN)-PAA-biotin and Neu5Aca2-3Galb1-4GlcNAcb (6'SLN)-PAA-biotin (GlycoTech, Rockville, MD, USA) at $4{ }^{\circ} \mathrm{C}$ overnight and blocked with PBS containing $2 \%$ skim milk powder before incubating with tested live virus in triplicate. Then, specific primary antibodies and HRP-conjugated anti-IgG secondary antibodies were added sequentially into the well to react with the virus. Finally, tetramethylbenzidine was used as a chromogenic substrate by terminating the reaction with $1 \mathrm{M} \mathrm{H}_{2} \mathrm{SO}_{4}$, and the absorbance at $450 \mathrm{~nm}$ was read for curve plotting.

As shown in Figure 1, the wild-type HD/05 virus showing complete $\alpha-2,3$ SA specificity and the 2009 pandemic H1N1 virus A/California/04/2009 (CA/09) binding selectively to $\alpha-2,6 \mathrm{SA}$ were used as controls. The single amino acid substitutions K90R, K222Q, S227R, N244H and A266T in HA did not obviously affect the viral binding specificity to $\alpha-2,3$ receptors at all, as compared with $\mathrm{HD} / 05$ virus. However, only the T160A mutant acquired affinity to $\alpha-2,6$ receptors yet retained affinity to $\alpha-2,3$ receptors, partially coincident with our previous publication indicating that this T160A-induced deglycosylation at site $158 \mathrm{~N}$ contributed to the recognition of the human-type receptors as evidenced by hemagglutinin assay still with substantial agglutination to the $\alpha-2,3$ sialidase pretreated goose red blood cells [23].

An experiment was conducted in guinea pigs to further investigate whether the T160A substitution of HA affected the replication of the H5N1 virus. Groups of four serologically $\mathrm{H} 5$-negative female animals were initially anesthetized with pentobarbital sodium $(50 \mathrm{mg} / \mathrm{kg})$, and inoculated intranasally with $10^{6} \mathrm{EID}_{50}$ of the tested viruses in a volume of $300 \mu \mathrm{L}(150 \mu \mathrm{L}$ per nostril). Two animals from each group were humanely euthanized on day 3 post inoculation (pi) for virus titration from tissue samples of nasal wash, trachea, lung, kidney, spleen and 


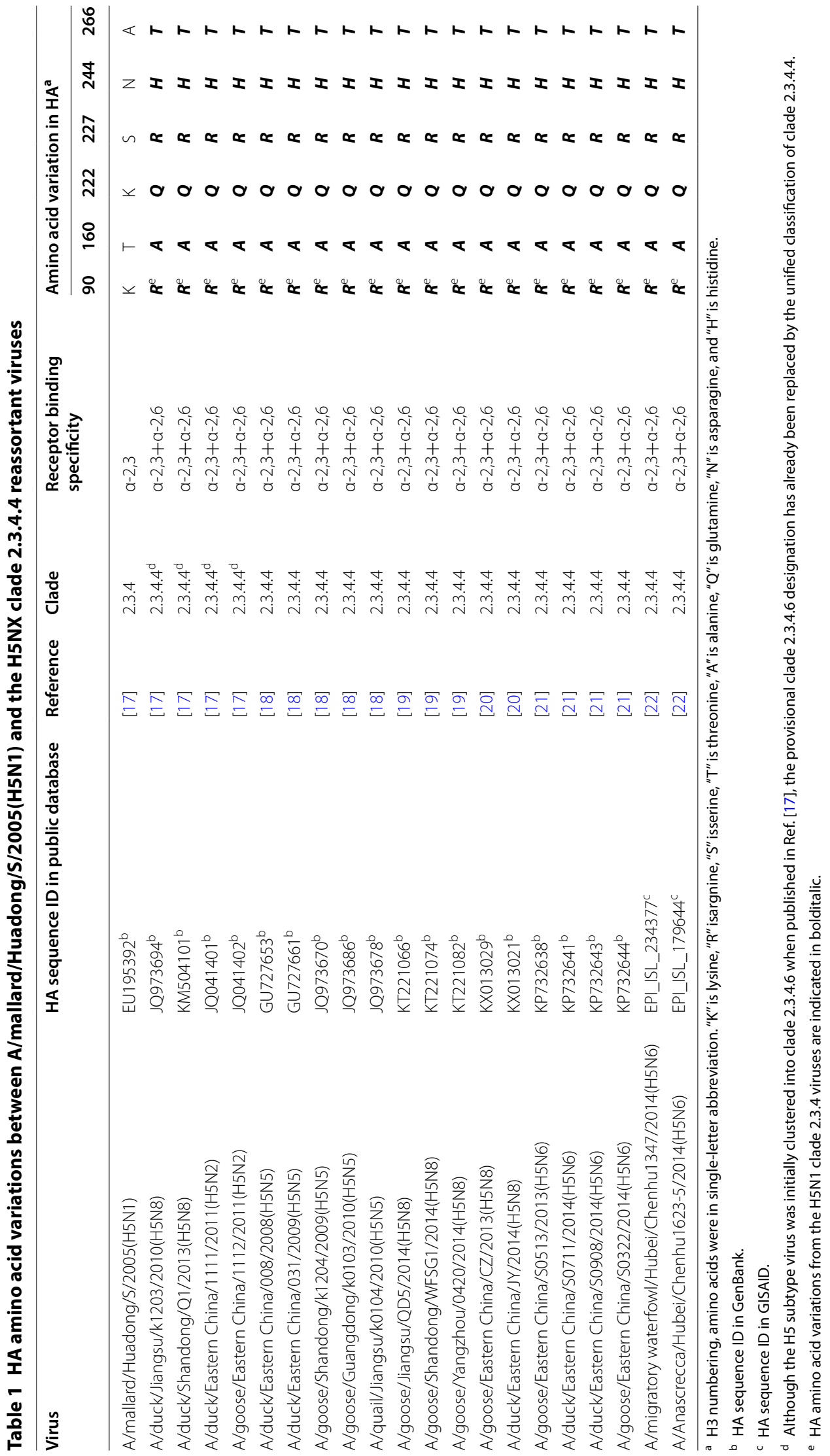



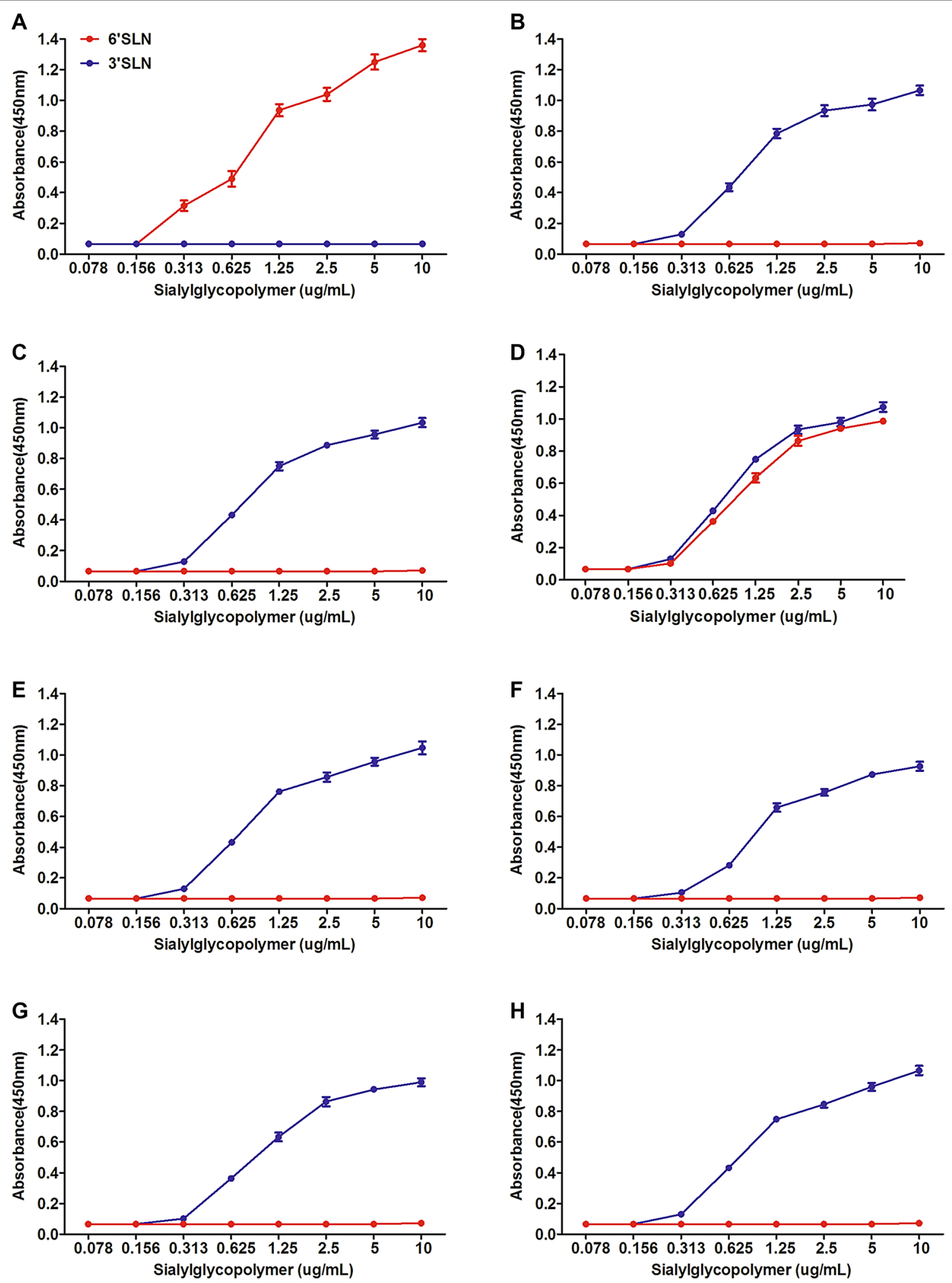

Figure 1 Solid-phase receptor-binding assay of HA mutants based on HD/05 virus. Solid-phase receptor-binding assay of human isolate CA/09 (A), poultry isolate HD/05 (B), HD-90R virus $(\mathbf{C}), H D-160 A$ virus $(\mathbf{D}), H D-222 Q$ virus $(\mathbf{E}), H D-227 R$ virus $(\mathbf{F}), H D-244 H$ virus $(\mathbf{G})$ and HD-266T virus (H). Direct viral binding to either 3'SLN-PAA-biotin or 6'SLN-PAA-biotin sialylglycopolymers was determined. Representative data from three independent binding experiments are shown. 
brain. The remaining two animals were observed for signs of disease and death during a two-week period.

From Table 2, we found that when the 160A mutation was introduced in the HA of $\mathrm{HD} / 05$ virus, the replication of the mutated virus (HD-160A) in vivo dramatically increased. The mutant virus could replicate in the nose, lung and trachea of the guinea pigs with the highest titer level of $4.5 \pm 1.2 \log _{10} \mathrm{EID}_{50} / \mathrm{mL}$, whereas the wild type $\mathrm{HD} / 05$ viruses were just detected in the lungs. However, virus was not recovered from the brains, kidneys or spleens of any of the H5N1 inoculated animals. Although no obvious disease signs were observed during 2 weeks pi, seroconversion was detected in both of the animals challenged with the mutated HD-160A virus but not identified in the HD/05-inoculated group.

For viral contact transmission studies, three animals per group were infected intranasally at the dose of $10^{6}$ EID $_{50}$ and housed in a cage placed inside a negativepressure isolator. Another three naive animals were put into the same cage $24 \mathrm{~h}$ later to act as the contact counterparts. Nasal washes were collected at 2-day intervals since day 2 pi ( 1 day post contact) and stored at $-70{ }^{\circ} \mathrm{C}$ until use for virus titration in chicken embryonated in eggs. All exposed animals were checked for seroconversion at day $14 \mathrm{pi}$ via determination of hemagglutinin inhibition (HI) antibodies. To prevent inadvertent mechanical transmission of virus from investigators, the contact guinea pigs were always treated first, and operating implements were changed between animals. These studies were performed under ambient conditions of $20-22{ }^{\circ} \mathrm{C}$ and $20-40 \%$ relative humidity. The airflow in the isolator was kept horizontal with a constant speed of $0.1 \mathrm{~m} / \mathrm{s}$.

As shown in Figure 2, the mutated HD-160A virus was detected in the nasal washes of all three inoculated guinea pigs from days 2 through $6 \mathrm{pi}$, and was also detected in two of the three contact animals between days 4 and 8 pi. In contrast, virus was not recovered from the nasal washes of any challenged guinea pigs after day 2 pi and of any contact animals in the group with the inoculum of wild-type HD/05 virus. Furthermore, seroconversion was also observed in three inoculated and two contact animals in the groups of the mutated HD$160 \mathrm{~A}$ virus, but totally negative in the $\mathrm{HD} / 05$ virus group (Table 2).

\section{Discussion}

Considering that the Asian lineage HPAI H5 subtype avian influenza viruses continuously expand both their geographical distribution and host range, whether they have gradually acquired efficient transmissibility between humans is of great concern. Although the natural isolates have still been deficient of such ability among people, two recent experimental studies report that reassortant $\mathrm{H} 5 \mathrm{~N} 1$ viruses with certain mutations in HA could gain the function of droplet transmission in a ferret model [24, 25]. According to submitted genome sequences in GenBank and GISAID, H5N1 clade 2.3.4 virus has caused the most human infections in China since 2005. In addition, the reassortant $\mathrm{H} 5 \mathrm{~N} 6$ virus within currently prevalent H5NX subclade 2.3.4.4 possessing dual affinity to $\alpha-2,3$ and $\alpha-2,6$ receptors, has also resulted in human death. Therefore, such above mentioned H5 viruses all pose a potential pandemic threat. In the present study, we compared the HA sequences of the previously described H5 viruses showing divergent receptor binding property to focus on potential adapted amino acid substitutions. And their effect on conferring viral affinity to $\alpha-2,6$ receptors and transmission among mammalian models were then evaluated, based on the genetic backbone of a clade 2.3.4 virus preferentially binding to $\alpha-2,3$ receptors. The results show that the single T160A substitution, which simultaneously led to the loss of glycosylation site at position $158 \mathrm{~N}$ in HA dramatically enhanced the viral specificity

Table 2 Replication and contact transmission of HD-160A virus in guinea pigs

\begin{tabular}{|c|c|c|c|c|c|c|c|c|c|}
\hline \multirow[t]{4}{*}{ Virus } & \multicolumn{7}{|c|}{ Replication in guinea pigs } & \multirow{3}{*}{\multicolumn{2}{|c|}{$\begin{array}{l}\text { Contact transmission } \\
\text { in guinea pigs } \\
\begin{array}{l}\text { Seroconversion: posi- } \\
\text { tive/total (HI titers) }\end{array}\end{array}$}} \\
\hline & \multicolumn{6}{|c|}{ Virus titers determined on day 3 post inoculation in } & \multirow{3}{*}{$\begin{array}{l}\text { Seroconversion: positive/ } \\
\text { total }\end{array}$} & & \\
\hline & \multirow{2}{*}{$\begin{array}{l}\text { Nasal wash } \\
\left(\log _{10} \mathrm{EID}_{50} \pm \mathrm{SD} / \mathrm{mL}\right)\end{array}$} & \multicolumn{5}{|c|}{ Organ $\left(\log _{10} \mathrm{EID}_{50} \pm \mathrm{SD} / \mathrm{g}\right)$} & & & \\
\hline & & Lung & Trachea & Spleen & Kidney & Brain & & Inoculated & Contact \\
\hline HD-160A & $4.5 \pm 1.2$ & $2.5 \pm 0.2$ & $0.8 \pm 0.1$ & $-{ }^{\mathrm{a}}$ & - & - & $2 / 2$ & $3 / 3(40,80,40)$ & $2 / 3(0,20,20)$ \\
\hline HD/05 & - & $1.2 \pm 0.2$ & - & - & - & - & $0 / 2$ & $0 / 3$ & $0 / 3$ \\
\hline
\end{tabular}

Groups of four guinea pigs were challenged intranasally with $10^{6} \mathrm{EID}_{50}$ of either test viruses in a volume of $300 \mu \mathrm{L}(150 \mu \mathrm{L}$ per nostril), of which two animals from each group were euthanized on day 3 pi. Tissue samples involving nasal wash, lung, trachea, spleen, kidney and brain were collected for virus titration in eggs. Sera from the remaining two animals were collected at the end of the two-week observation period, and pretreated overnight with the receptor-destroying enzyme of Vibrio cholerae.

a Virus was not recovered from the undiluted tissue sample. 

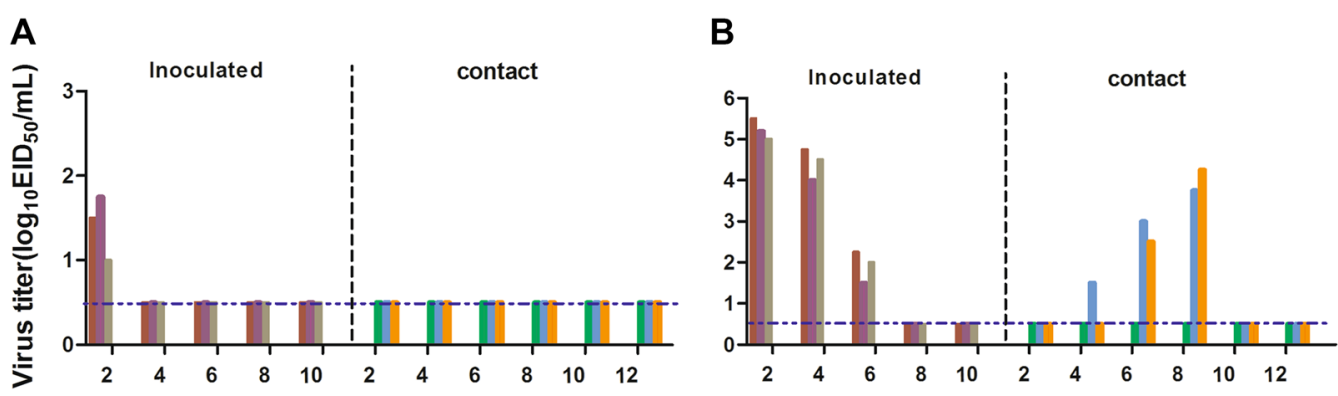

Days post-inoculation

Figure 2 Transmission of HD/05 virus and HD-160A virus in guinea pigs. (A) HD/05 virus and (B) HD-160A virus. Groups of three guinea pigs were challenged intranasally with $10^{6} \mathrm{EID}_{50}$ of either test viruses, and additional three contact guinea pigs were placed in the same cage $24 \mathrm{~h}$ after the inoculation. Nasal washes were collected every two days from all the animals since day 2 pi for detection of virus shedding. Each color bar indicates the viral titer from an individual animal. The dashed horizontal lines in the two panels represent the lower limit of detection.

for human-type receptors, and the HA mutant could spread efficiently in guinea pigs.

Glycosylation is an essential posttranslational modification for HA, actively involved in certain biological functions such as evasion of host immunity, HA cleavability and receptor binding [26]. The addition or elimination of the glycosylation site in close proximity to the RBD has been shown to modulate receptor binding specificity, antigenicity, and pathogenicity of influenza viruses of different HA subtypes and lineages [23, 27-29]. Furthermore, lack of the $158 \mathrm{~N}$ glycosylation site in HA was found to be crucial for the transmissibility of H5N1 virus in mammals. It was demonstrated that the additive glycosylation at $158 \mathrm{~N}$ due to an A160T mutation on a clade 2.2 virus, abolished the viral ability to bind to the $\alpha-2,6 \mathrm{SA}$ and transmission in guinea pigs [30]. Moreover, reassortant $\mathrm{H} 5 \mathrm{~N} 1$ viruses of clade 1 and 2.1.3 HA with N158D-induced deglycosylation were capable of airborne transmission in a ferret model $[24,25]$. However, whether this variation of the glycosylation pattern still works in the HA backbone of clade 2.3.4 influenza viruses remains unclear.

Here, we verified that the T160A mutation enabled $\mathrm{H} 5 \mathrm{~N} 1$ clade 2.3.4 virus to not only acquire binding affinity for human-type glycans but also transmit among guinea pigs. Although $\alpha-2,6$ receptor binding property does not necessarily imply successful human transmission requiring additional synergy, mutants with high avidity for both $\alpha-2,3$ and $\alpha-2,6$ receptors may be intermediates during the evolution of novel $\mathrm{H} 5$ reassortants that could infect both poultry and humans to increase the risk of an influenza pandemic. Therefore, continued routine surveillance of $\mathrm{H} 5$ variants possessing dual receptor affinity is indispensable as an early warning system, and the presence or absence of the $158 \mathrm{~N}$ glycosylation site could serve as an important molecular marker for assessing pandemic potential of $\mathrm{H} 5$ subtype avian influenza isolates.

\section{Additional file}

\section{Additional file 1. Cartoon representation of the HA structure of A/} mallard/Huadong/S/2005. The model was generated by automated homology modeling using SWISS-MODEL based on the template of PDB (ID: 4jul). The receptor-binding domain (RBD) constituting with amino acids 188-190, 134-138, 221-228, 98,153 and 183 of HA1 (H3 numbering), according to reference [9], were colored yellow for clarity. The six divergent amino acids discussed in the text were colored gray, of which simultaneously located in RBD were labeled orange. The six specific substitutions were shown as sticks in the magnified side pictures, respectively. " $K$ " is lysine, " $R$ " is arginine, "T" is threonine, " $Q$ " isglutamine, " $\mathrm{S}$ " is serine, " $N$ " is asparagine, " $\mathrm{H}$ " is histidine and " $\mathrm{A}$ " is alanine.

\section{Abbreviations}

HA: hemagglutinin; HPAl: highly pathogenic avian influenza; SA: sialic acid; RBD: receptor-binding domain; NA: neuraminidase; GISAID: global initiative on sharing all influenza data; HD/05: A/mallard/Huadong/S/2005; CA/09: A/ California/04/2009; SPF: specific-pathogen-free; HRP: horse radish peroxidase; $\mathrm{EID}_{50}: 50 \%$ embryo infectious dose titer; pi: post inoculation; $\mathrm{HI}$ : hemagglutinin inhibition.

\section{Competing interests}

The authors declare that they have no competing interests.

\section{Authors' contributions}

$M G$ and QL participated in designing the study, performed the experiments and drafted the manuscript. RG, DH, YX and LX helped in the animal experiment. HX assisted with the HA structure modeling. XW, JH, XL (Xiaowen Liu) and $\mathrm{SH}$ contributed to sample testing. DP and $\mathrm{XJ}$ guided data analysis. XL (Xiufan Liu) conceived the study, provided consultation and coordination. All authors read and approved the final manuscript.

\section{Acknowledgements}

This work was funded by the China Postdoctoral Science Foundation (No. 156471), the Natural Science Foundation of Jiangsu Province (No. BK20130442), the Postdoctoral Science Foundation of Jiangsu Province (No. 1501075C), the Open Project Program of Jiangsu Key Laboratory of Zoonosis (No. R1506), the Yangzhou University Science and Technology Innovation Program (No. 2015CXJ059), the Earmarked Fund for Modern Agro-Industry 
Technology Research System (No. nycytx-41-G07) and the Priority Academic Program Development of Jiangsu Higher Education Institutions (PAPD).

\section{Author details}

${ }^{1}$ College of Veterinary Medicine, Yangzhou University, Yangzhou, Jiangsu 225009, China. ${ }^{2}$ Jiangsu Key Laboratory of Zoonosis, Yangzhou University, Yangzhou, Jiangsu 225009, China. ${ }^{3}$ Yangzhou Entry-Exit Inspection and Quarantine Bureau, Yangzhou, Jiangsu 225009, China. ${ }^{4}$ Jiangsu Co-Innovation Center for the Prevention and Control of Important Animal Infectious Disease and Zoonoses, Yangzhou, Jiangsu 225009, China.

Received: 9 October 2016 Accepted: 12 December 2016 Published online: 06 February 2017

\section{References}

1. Guan Y, Smith GJ (2013) The emergence and diversification of panzootic H5N1 influenza viruses. Virus Res 178:35-43

2. Watanabe Y, Ibrahim MS, Ikuta K (2013) Evolution and control of H5N1. A better understanding of the evolution and diversity of $\mathrm{H} 5 \mathrm{~N} 1$ flu virus and its host species in endemic areas could inform more efficient vaccination and control strategies. EMBO Rep 14:117-122

3. Matrosovich M, Tuzikov A, Bovin N, Gambaryan A, Klimov A, Castrucci MR, Donatelli I, Kawaoka Y (2000) Early alterations of the receptor-binding properties of $\mathrm{H} 1, \mathrm{H} 2$, and $\mathrm{H} 3$ avian influenza virus hemagglutinins after their introduction into mammals. J Virol 74:8502-8512

4. Shinya K, Ebina M, Yamada S, Ono M, Kasai N, Kawaoka Y (2006) Avian flu: influenza virus receptors in the human airway. Nature 440:435-436

5. Tambunan US, Ramdhan (2010) Identification of sequence mutations affecting hemagglutinin specificity to sialic acid receptor in influenza $\mathrm{A}$ virus subtypes. Bioinformation 5:244-249

6. Vines A, Wells K, Matrosovich M, Castrucci MR, Ito T, Kawaoka Y (1998) The role of influenza A virus hemagglutinin residues 226 and 228 in receptor specificity and host range restriction. J Virol 72:7626-7631

7. Glaser L, Stevens J, Zamarin D, Wilson IA, Garcia-Sastre A, Tumpey TM, Basler CF, Taubenberger JK, Palese P (2005) A single amino acid substitution in 1918 influenza virus hemagglutinin changes receptor binding specificity. J Virol 79:11533-11536

8. Stevens J, Blixt O, Chen LM, Donis RO, Paulson JC, Wilson IA (2008) Recent avian $\mathrm{H} 5 \mathrm{~N} 1$ viruses exhibit increased propensity for acquiring human receptor specificity. J Mol Biol 381:1382-1394

9. Stevens J, Blixt O, Tumpey TM, Taubenberger JK, Paulson JC, Wilson IA (2006) Structure and receptor specificity of the hemagglutinin from an H5N1 influenza virus. Science 312:404-410

10. Suzuki Y (2005) Sialobiology of influenza: molecular mechanism of host range variation of influenza viruses. Biol Pharm Bull 28:399-408

11. Claes F, Morzaria SP, Donis RO (2016) Emergence and dissemination of clade 2.3.4.4 H5Nx influenza viruses-how is the Asian HPAl H5 lineage maintained. Curr Opin Virol 16:158-163

12. Zeng X, Chen P, Liu L, Deng G, Li Y, Shi J, Kong H, Feng H, Bai J, Li X, Shi W, Tian $\mathrm{G}$, Chen $\mathrm{H}$ (2016) Protective efficacy of an $\mathrm{H} 5 \mathrm{~N} 1$ inactivated vaccine against challenge with lethal $\mathrm{H} 5 \mathrm{~N} 1, \mathrm{H} 5 \mathrm{~N} 2, \mathrm{H} 5 \mathrm{~N} 6$, and $\mathrm{H} 5 \mathrm{~N} 8$ influenza viruses in chickens. Avian Dis 60:253-255

13. Pasick J, Berhane Y, Joseph T, Bowes V, Hisanaga T, Handel K, Alexandersen S (2015) Reassortant highly pathogenic influenza A H5N2 virus containing gene segments related to Eurasian H5N8 in British Columbia, Canada, 2014. Sci Rep 5:9484

14. Chu DH, Okamatsu M, Matsuno K, Hiono T, Ogasawara K, Nguyen LT, Van Nguyen L, Nguyen TN, Nguyen TT, Van Pham D, Nguyen DH, Nguyen TD, To TL, Van Nguyen H, Kida H, Sakoda Y (2016) Genetic and antigenic characterization of $\mathrm{H} 5, \mathrm{H} 6$ and $\mathrm{H} 9$ avian influenza viruses circulating in live bird markets with intervention in the center part of Vietnam. Vet Microbiol 192:194-203
15. Butler J, Stewart CR, Layton DS, Phommachanh P, Harper J, Payne J, Evans RM, Valdeter S, Walker S, Harvey G, Shan S, Bruce MP, Rootes CL, Gough TJ, Rohringer A, Peck GR, Fardy SJ, Karpala AJ, Johnson D, Wang J, Douangngeun B, Morrissy C, Wong FY, Bean AG, Bingham J, Williams DT (2016) Novel reassortant H5N6 influenza A virus from the Lao People's Democratic Republic is highly pathogenic in chickens. PLoS One 11:e0162375

16. Shen YY, Ke CW, Li Q, Yuan RY, Xiang D, Jia WX, Yu YD, Liu L, Huang C, Qi WB, Sikkema R, Wu J, Koopmans M, Liao M (2016) Novel reassortant avian influenza A(H5N6) viruses in humans, Guangdong, China, 2015. Emerg Infect Dis 22:1507-1509

17. Li Q, Wang X, Gu M, Zhu J, Hao X, Gao Z, Sun Z, Hu J, Hu S, Wang X, Liu X, Liu X (2014) Novel H5 clade 2.3.4.6 viruses with both alpha-2,3 and alpha-2,6 receptor binding properties may pose a pandemic threat. Vet Res 45:127

18. Li Q, Wang X, Gao Z, Sun Z, Cui Z, Duan Z, Li J, Gu M, Wang X, Hu J, Liu X, Liu $X$ (2015) Novel reassortant H5N5 viruses bind to a human-type receptor as a factor in pandemic risk. Vet Microbiol 175:356-361

19. Li J, Gu M, Liu D, Liu B, Jiang K, Zhong L, Liu K, Sun W, Hu J, Wang X, Hu S, Liu X, Liu X (2016) Phylogenetic and biological characterization of three K1203 (H5N8)-like avian influenza A virus reassortants in China in 2014. Arch Virol 161:289-302

20. Wang X, Meng F, Wang D, Liu X, Chen S, Qin T, Peng D, Liu X (2016) Characteristics of two highly pathogenic avian influenza H5N8 viruses with different pathogenicity in mice. Arch Virol 161:3365-3374

21. Sun H, Pu J, Wei Y, Sun Y, Hu J, Liu L, Xu G, Gao W, Li C, Zhang X, Huang Y, Chang KC, Liu X, Liu J (2016) Highly pathogenic avian influenza H5N6 viruses exhibit enhanced affinity for human type sialic acid receptor and in-contact transmission in model ferrets. J Virol 90:6235-6243

22. Bi Y, Liu H, Xiong C, Di L, Shi W, Li M, Liu S, Chen J, Chen G, Li Y, Yang G, Lei Y, Xiong Y, Lei F, Wang H, Chen Q, Chen J, Gao GF (2016) Novel avian influenza A ( $15 \mathrm{~N} 6)$ viruses isolated in migratory waterfowl before the first human case reported in China, 2014. Sci Rep 6:29888

23. Zhang $X$, Chen $S$, Jiang $Y$, Huang $K$, Huang J, Yang D, Zhu J, Zhu Y, Shi S, Peng D, Liu X (2015) Hemagglutinin glycosylation modulates the pathogenicity and antigenicity of the H5N1 avian influenza virus. Vet Microbiol 175:244-256

24. Herfst S, Schrauwen EJ, Linster M, Chutinimitkul S, de Wit E, Munster VJ, Sorrell EM, Bestebroer TM, Burke DF, Smith DJ, Rimmelzwaan GF, Osterhaus AD, Fouchier RA (2012) Airborne transmission of influenza A/H5N1 virus between ferrets. Science 336:1534-1541

25. Imai M, Watanabe T, Hatta M, Das SC, Ozawa M, Shinya K, Zhong G, Hanson A, Katsura H, Watanabe S, Li C, Kawakami E, Yamada S, Kiso M, Suzuki Y, Maher EA, Neumann G, Kawaoka Y (2012) Experimental adaptation of an influenza $\mathrm{H} 5 \mathrm{HA}$ confers respiratory droplet transmission to a reassortant $\mathrm{H} 5 \mathrm{HA} / \mathrm{H} 1 \mathrm{~N} 1$ virus in ferrets. Nature 486:420-428

26. Klenk HD, Wagner R, Heuer D, WolffT (2002) Importance of hemagglutinin glycosylation for the biological functions of influenza virus. Virus Res 82:73-75

27. Teng Q, Xu D, Shen W, Liu Q, Rong G, Li X, Yan L, Yang J, Chen H, Yu H, Ma W, Li Z (2016) A single mutation at position 190 in hemagglutinin enhances binding affinity for human type sialic acid receptor and replication of H9N2 avian influenza virus in mice. J Virol 90:9806-9825

28. Wang W, Lu B, Zhou H, Suguitan AL Jr, Cheng X, Subbarao K, Kemble G, Jin $H(2010)$ Glycosylation at $158 \mathrm{~N}$ of the hemagglutinin protein and receptor binding specificity synergistically affect the antigenicity and immunogenicity of a live attenuated H5N1 ANietnam/1203/2004 vaccine virus in ferrets. J Virol 84:6570-6577

29. Abe Y, Takashita E, Sugawara K, Matsuzaki Y, Muraki Y, Hongo S (2004) Effect of the addition of oligosaccharides on the biological activities and antigenicity of influenza A/H3N2 virus hemagglutinin. J Virol 78:9605-9611

30. Gao Y, Zhang $Y$, Shinya K, Deng G, Jiang Y, Li Z, Guan Y, Tian G, Li Y, Shi J, Liu L, Zeng X, Bu Z, Xia X, Kawaoka Y, Chen H (2009) Identification of amino acids in $\mathrm{HA}$ and $\mathrm{PB} 2$ critical for the transmission of $\mathrm{H} 5 \mathrm{~N} 1$ avian influenza viruses in a mammalian host. PLoS Pathog 5:e1000709 